https://helda.helsinki.fi

\title{
Jailhouse self-induced lesions by misuse of salbutamol inhaler
}

\section{Charlier, Philippe}

2019-09

Charlier , P , Deo , S \& Kluger , N 2019 , ' Jailhouse self-induced lesions by misuse of salbutamol inhaler ' , International Journal of Dermatology , vol. 58 , no. 9 , pp. E165-E167 . https://doi.org/10.1111/i]

http://hdl.handle.net/10138/312953

https://doi.org/10.1111/ijd.14434

draft

Downloaded from Helda, University of Helsinki institutional repository.

This is an electronic reprint of the original article.

This reprint may differ from the original in pagination and typographic detail.

Please cite the original version. 


\section{Correspondence}

\section{Jailhouse self-induced lesions by misuse of salbutamol inhaler}

Deliberate misuse of salbutamol inhaler in order to self-inflict skin injuries has been reported in the literature mostly among kids and teenagers, usually because of psychological distress or just for fun. ${ }^{1-8}$ We report a case in an adult inmate in order to have a "pseudo-tattooed" letter on his skin.

A 22-year-old inmate from Mali who was transferred from one prison to another underwent medical examination upon arrival. His history was notable for chronic asthma treated by intermittent salbutamol nebulization. Examination of the skin on the left arm revealed six well-delimited and regular hypopigmented macules with a central hyperpigmentation depicting roughly the letter «D» (Fig. 1). The rest of the physical examination was unremarkable. After inquiry, the patient acknowledged selfinflicting the lesions by repeatedly applying the nozzle of salbutamol on the skin and discharging blasts to the arm. Icy cold sensation after inflations resulted in the development of hypochromic macules. Each lesion perfectly matched the shape of the inhaler's mouthpiece exhaust (Fig. 2). The global

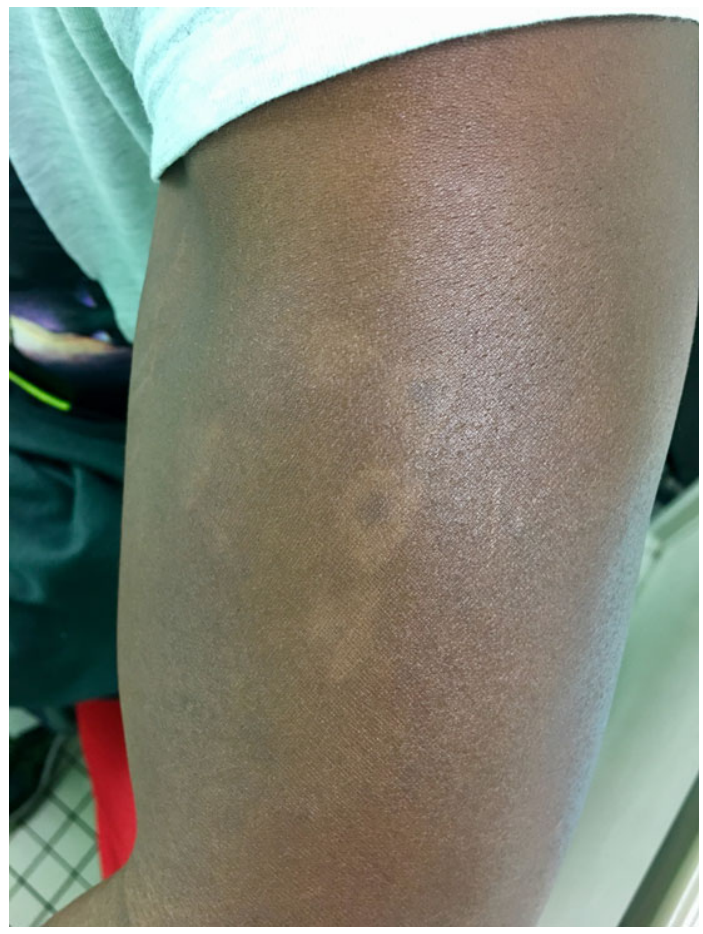

Figure 1 Hypopigmented lesions with central hyperpigmentation of the left arm displaying a "D" letter

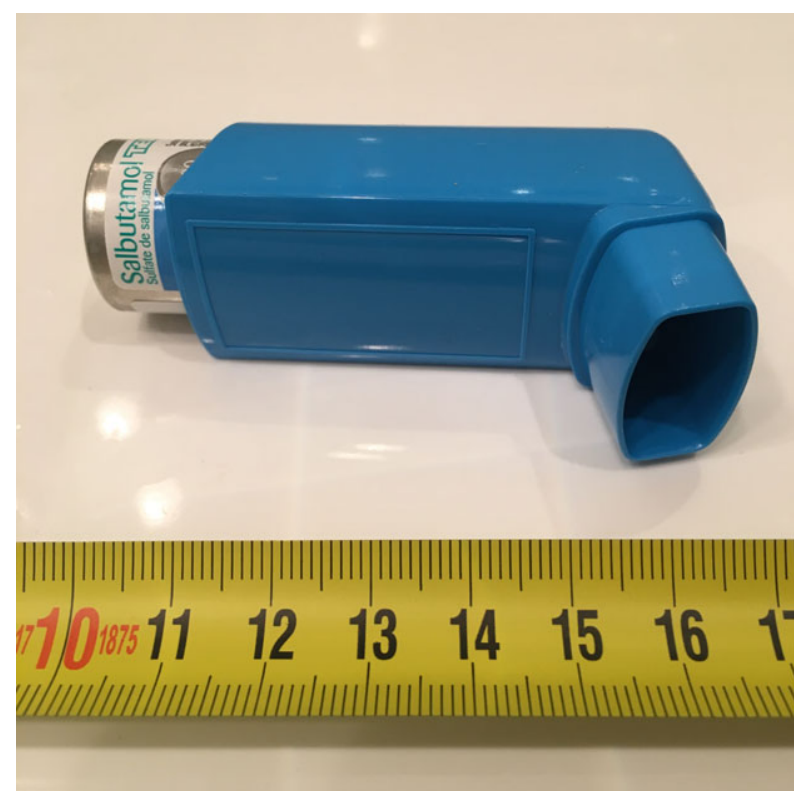

Figure 2 Salbutamol mouthpiece shape perfectly matches the skin lesions

«D» shape related to the first letter of the patient's nickname. The patient gave up misusing salbutamol inhaler, and the lesions slowly disappeared without any sequela 2 months later.

Several cases of self-induced skin burns of the hands and upper limbs have been reported after misuse of salbutamol inhaler. They are either performed in a context of psychological distress and deliberate self-harm ${ }^{1,7}$ or as a "recreational" activity, usually in school in the company of several other schoolmates. ${ }^{2,4-6,8}$ Mechanisms and reasons for such behavior are usually revealed after questioning the patient. In our case, salbutamol inhaler was misused in order to obtain markings on the arm. Tattooing is a common practice in prisons, but most tattoos are gotten through unsavory and unsafe ways. ${ }^{9}$ The lack of hygiene and poor sterilization methods used expose individuals to transmission of blood-borne diseases such as hepatitis ${ }^{10}$ or HIV. The inmate here chose a "safer" way to get a tattoo-like mark, albeit transient.

Mechanisms for skin injury may include (i) cold-induced skin damage, (ii) physical injury from the impact of high-velocity gas against the skin, and (iii) chemical direct injury because of the active component or excipients (pharmaceutical, preservative of propellant aerosol). ${ }^{2,7}$ The report illustrates the resourcefulness of inmates to self-harm themselves. 


\author{
Philippe Charlier ${ }^{1,2,3, *}$ \\ Saudamini Deo ${ }^{1}$ \\ Nicolas Kluger ${ }^{4}$ iD \\ ${ }^{1}$ UFR of Health Sciences (UVSQ DANTE Laboratory \\ EA4498), Montigny-Le-Bretonneux, France \\ ${ }^{2}$ Museum of Quai Branly, Paris, France \\ ${ }^{3} \mathrm{CASH} \&$ IPES, Nanterre, France \\ ${ }^{4}$ Department of Dermatology, Allergology and Venereology, \\ Helsinki University Central Hospital, Helsinki, Finland \\ *E-mail: Philippe.charlier@uvsq.fr
}

Funding: None.

Conflict of interest: None declared.

doi: $10.1111 /$ ijd. 14434

\section{References}

1 Akhtar S, Majumder S. An unusual self inflicted burn in an asthmatic patient. Burns 2003; 29: 191-192.
2 Patel R, Potter SJ. Ten puffs too many. Arch Dis Child 2004; 89: 1129.

3 Connolly M, Kennedy CT. Inhaler-induced pigmentary changes in a 14-year-old girl. Pediatr Dermatol 2007; 24: 499-500.

4 Arun B, Jacob J, Byrne JP. An uncommon burn. Br J Dermatol 2009; 160: 197.

5 Kale A, Shackley F. Accidental cutaneous burns secondary to salbutamol metered dose inhaler. Case Rep Med 2010; 2010: 201809.

6 Bonniaud P, Georges M, Blanc-Caille M, et al. Salbutamol inhaler misuse resulting in skin burn. J Allergy Clin Immunol 2011; 127: 295.

7 Terrier-Lenglet A, Derra HC, Devoldere C, et al. Misuse of a salbutamol inhaler causing skin burns. Therapie 2012; 67 : 59-61.

8 Le Cordel N. défi "Ventoline". Ann Dermatol Venereol 2018; 145 : s194-s195.

9 Hellard ME, Aitken CK, Hocking JS. Tattooing in prisonsnot such a pretty picture. Am J Infect Control 2007; 35: 477-480.

10 Poulin C, Courtemanche Y, Serhir B, et al. Tattooing in prison: a risk factor for HCV infection among inmates in the Quebec's provincial correctional system. Ann Epidemiol 2018; 28: 231-235. 